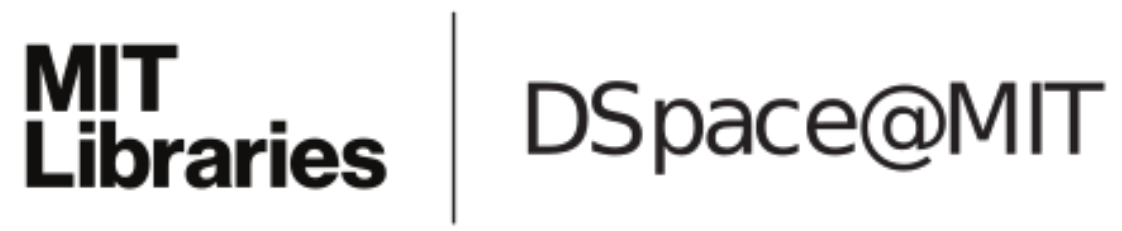

\author{
MIT Open Access Articles
}

RFID diagnostics of promotion execution

The MIT Faculty has made this article openly available. Please share how this access benefits you. Your story matters.

Citation: Hacker, Patrick A., Christian Floerkemeier, Sanjay Sarma, and Gunther Schuh. RFID Diagnostics of Promotion Execution. In 2010 IEEE International Conference on RFID (IEEE RFID 2010), 134-140. Institute of Electrical and Electronics Engineers, 2010. () Copyright 2010 IEEE.

As Published: http://dx.doi.org/10.1109/RFID.2010.5467278

Publisher: Institute of Electrical and Electronics Engineers

Persistent URL: http://hdl.handle.net/1721.1/79434

Version: Final published version: final published article, as it appeared in a journal, conference proceedings, or other formally published context

Terms of Use: Article is made available in accordance with the publisher's policy and may be subject to US copyright law. Please refer to the publisher's site for terms of use. 


\title{
RFID Diagnostics of Promotion Execution
}

\author{
Patrick A. Hacker ${ }^{*}$, Christian Floerkemeier ${ }^{+}$Sanjay Sarma ${ }^{+}$and Günther Schuh ${ }^{*}$ \\ *Fraunhofer IPT, Aachen, Germany
}

${ }^{+}$Auto-ID Lab, Massachusetts Institute of Technology, Cambridge, USA

patrick.hacker@ipt.fraunhofer.de, floerkem@mit.edu, sesarma@mit.edu, guenther.schuh@ipt.fraunhofer.de

\begin{abstract}
Previous studies have shown that many consumer goods manufacturers believe that their promotions are not well executed in retail stores. One common concern is that in-store promotions are not synchronized with television and online advertising campaigns. In recent years, RFID has been actively promoted as a tool to improve in-store promotion execution. This paper presents the results of a study in which promotional displays were tagged with RFID tags and tracked as they moved from a retail distribution center to a number of different retail stores. The analysis shows that only $28 \%$ of all displays are placed on the shop floor within $+/-3$ days of the official promotion launch. Our analysis suggests that by adjusting the timing of the delivery to the store the performance could be improved such that $87 \%$ of all displays are present on the shop floor within this time frame. The results confirm that RFID is a useful diagnostics tool to measure promotion execution performance and to identify business process shortcomings. The results also suggest that a continuous measurement via RFID is not required to improve performance.
\end{abstract}

Index Terms-RFID, promotion execution, business process analysis

\section{INTRODUCTION}

$\mathrm{R}$ ADIOFREQUENCY identification (RFID) has received significant attention in recent years to measure and improve supply chain performance [1]. In particular, the tagging of promotional displays has been considered because it does not require tagging of every case of goods moving through the supply chain [2]. In-store advertising via promotional displays also represents an important element of marketing for consumer goods manufacturers. The Veronis Suhler Stevenson Communications Industry Forecast shows that the total sum spent on promotional marketing in 2006 was about 44 billion USD [3]. As part of in-store advertising, consumer goods manufacturers have spent about 19 billion USD for point-of-purchase promotions according to [3].

Promotion campaigns typically comprise advertisements in the media, discounts on promoted products and special pointof-sale display on the sales floor that highlight the products promoted. For reasons of cost and focus, the media advertisements are limited to a distinct period of time and it is important to synchronize the advertisement campaign in the media with the execution on the sales floor $[4,5]$.

The consumer expects the promoted products to be available on the sales floor, if he or she sees the advertisements in the media. Execution problems with in-store promotional displays are common place. Bell et. al found in a study that $85 \%$ of all consumer goods manufacturers believe that their promotional dollars are spent ineffective [6]. Suppliers even have dedicated "Supplier Retail Operations" teams that visit individual stores to make sure that the promotional displays are present on the shop floor at the appropriate moment of time [2].

The contribution of this paper is two-fold. We present a case study where 1500 promotional displays were tagged in 40 promotion campaigns and their movement was tracked from a distribution center to the sales floor in ten retail stores. The results show to what extent promotional displays arrive in time on the shop floor. The paper also points to the causes of the lack of timeliness and suggest business process changes to address the problem. This paper also illustrates the idea of RFID as a diagnostics tool where RFID technology is deployed for a limited time to identify business process problems and make the appropriate business process changes. Previously, RFID technology was often deployed continuously and to help with day-to-day decision making and error prevention in real-time. Our analysis suggests that RFID can play an important role as a diagnostics tool.

The remainder of our paper is organized as follows. First we present relevant work. Before we analyze the results of the case study in Section IV, we describe the data capture process in Section III. Section V presents a discussion and we conclude in Section VI.

\section{RELATED WORK}

There are several studies that showed that the timely placement of promotions on the shop floor can increase sales. A Hewlett-Packard RFID study showed a sales increase of $140 \%$ for stores which executed the promotion correctly and only a $30 \%$ sales lift for the stores which are late in placing the displays on the sales floor [4]. Gillette discovered in an RFID study that sales of one particular product which was promoted by the manufacturer were $48 \%$ higher at stores which placed the promotion displays on the sales floor before the promotion started than those stores that moved them after promotion started [5]. Proctor \& Gamble and Gillette carried out several RFID pilot studies tracking promoted products. 
They found that stores that moved the promotion display on time had $61 \%$ better sales than those that moved the displays too late for an extraordinary time sensitive promotion. Furthermore they discovered in one study that over $33 \%$ of all displays were moved too late or not at all. In another study they found that only 6 out of 19 stores moved the displays out on time [7]. The results presented in this study agree with the findings in [7], but they also provide significantly more insights into the problem. Our results identify causes of the lack of timeliness and suggest how to address the problem through business process changes.

Duvall reported that suppliers see value in the use of RFID on promotional displays because it gives them real-time insights into what is going inside the individual retail store [8]. Today, they only know that a particular pallet of displays has arrived at the distribution center of the retailer. For suppliers, the real worry according to Duvall is whether the promotional displays have moved from the back rooms of individual stores to shop floor at the right time, and RFID tagging is giving suppliers a window "into that black hole" [8]. The case study presented in this paper indicates that it might not be necessary to deploy RFID technology and monitor the promotion execution in real-time and continuously. Instead, it might be sufficient to deploy RFID to identify business process changes that can lead to significantly improved promotion execution.

Other related work on promotion execution analyzed the out-of stock rates during promotions and possible causes of weak promotion execution. Gruen et. al found that the out-ofstock-rates of promotional products are doubled in comparison to the OOS-rates of non promotional products [9] Both Srinivasan et al. [10] and Hisashi Kurataa et al. [11] showed that the promotion execution issues can be traced back to the fact that the supplier is the main monetary beneficiary of promotion campaigns and the retailer is responsible for the execution. According to [4], promotions causes a significant burden on the sales floor force.

There is little related work that provides quantitative results detailing promotion execution. In fact, IBM and SAP found that about $70 \%$ of the CPG companies do not measure the result of their promotion campaigns.

\section{DATA CAPTURE}

The data were captured in the summer of 2007 by deploying RFID technology in the supply chain of a single US retailer. 1500 promotional displays were tagged and tracked as they were distributed from a single distribution center (DC) to ten different stores. One group of stores was located in the same city as the DC and the other group was located in a city about 250 miles away (cf.Figure 1). The figure also shows the number of tracked displays for each group of stores. The 1500 promotional displays tagged were part of 40 different promotion campaigns. As part of each campaign, multiple displays were delivered to each store for replenishment purposes. For the analysis presented in this paper, the first display of each campaign delivered to a particular store was of importance.

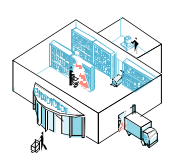

4 Stores

655 tagged Displays

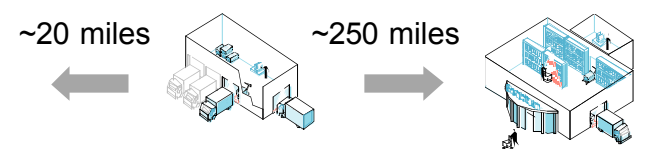

6 Stores

898 tagged Displays

\section{Figure 1: Distances between stores and DC}

The displays were tagged with passive RFID tags. Date and time was recorded when a case with displays or just a display passed an RFID reader. RFID readers were deployed at the shipping dock of the DC. At each store, RFID readers were installed at the receiving dock or the entrance to the back room. RFID readers were also installed at the door between the back room and the sales floor. Each of the displays carried a certain number of products. During the distribution process, the displays were shipped together with regular, nonpromotion products.

Each promotion had a start date and an end date. The length of the individual promotions varied as shown in Figure 2. A substantial part of the 1500 tagged displays were replenishment displays. In our analysis, we focused on the 229 displays that reached an individual store as the first display for a particular promotion campaign.

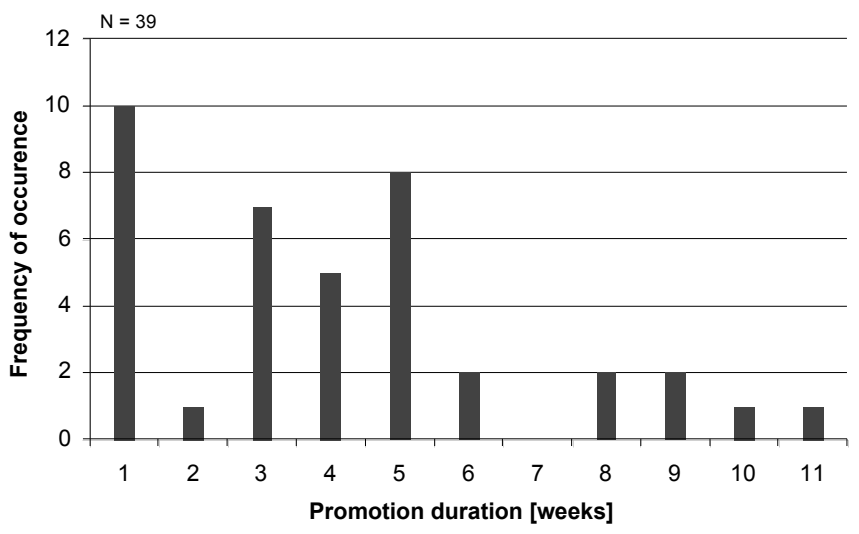

Figure 2: Histogram of promotion duration for the 39 campaigns investigated

False negative reads, where a particular RFID tag is not detected at a particular location, were compensated by redundant tagging of displays where possible. In other cases, potential false negative reads could not be clearly identified as such because the missing tag read could have also resulted form other causes, such as theft. In cases, where the traces were incomplete because of a false negative reads or other causes, the trace was not included in the analysis. This only happened in very few cases. During the data capture process, it was not possible to enforce that every display arriving at a store really carried a tag. There is thus the possibility that few displays arrived on the shop floor without being properly recorded. We ignored this possibility in our analysis given the low likelihood of a non-tagged promotional items entering the distribution process without passing through the distribution 
center where the deliveries were initiated. False positive reads, also sometimes referred to as ghost reads, did not represent a problem in this RFID deployment.

\section{RESUlts}

In this section, we analyze how timely the displays were placed on the shop floor relative to the launch of the promotion campaign with corresponding media advertisement campaigns.

\section{A. Timeliness of promotion execution}

Our results show that only $28 \%$ of the displays were placed within $+/-3$ days of the official launch of the promotion on the shop floor (cf. Figure 3). The duration of six days was chosen because it represents an acceptable delay. It does not have any special significance. At time " 0 ", the promotion launch, $60 \%$ of the promotional displays have been placed on $49 \%$ of all displays are placed on the sales floor

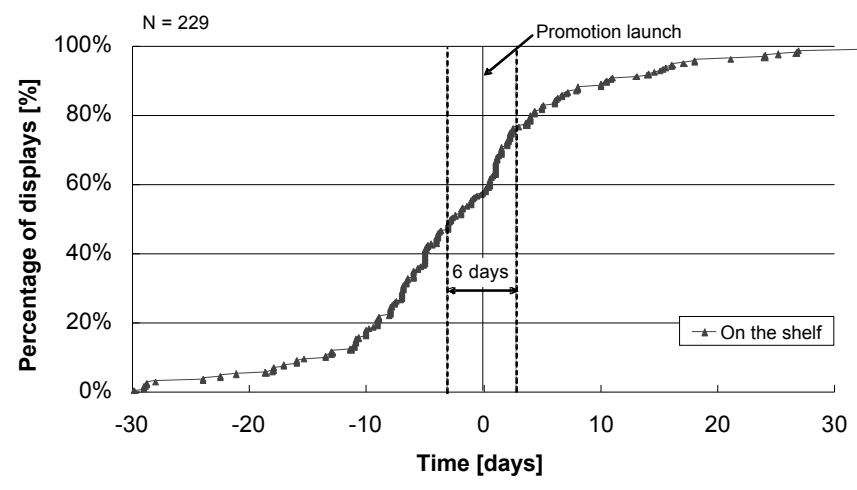

Figure 3: Cumulative distribution function of display arrival on the shop floor the shop floor. The majority of these displays were placed on the shop floor significantly before the launch of the promotion.

more than 3 days too early while $23 \%$ of all promotional displays are placed on the sales floor more than 3 days too late. This variability in the display arrival on the shop floor is especially concerning given that the average length of a promotion campaign is only 29 days (cf. Figure 2 ).

\section{B. Departure DC, Arrival at the Store and Placement on the Shop Floor}

In order to analyze the cause for the variability in the arrival of the promotion displays on the shop floor, we provide an analysis of the movement of the tagged promotion displays in this section. Figure 4 shows the cumulative distribution of when promotion cases were shipped, when they arrived at the retailer and when they were placed on the sales floor.

A significant amount of promotions are shipped too late, which results in $32 \%$ of all promotion displays not arriving at the retail store on the day of the promotion start. Figure 4 shows that $15 \%$ of all promotional displays even leave the DC after the promotion start date. The other $68 \%$ of the promotional displays tracked arrive before the launch, but the staff at the retail store places the majority of the displays on the shop floor before the launch.

\section{Transit time}

To determine the cause of the late arrival of the displays at the store, we analyze the distribution of the transit time (cf. Figure 5) and compare transit times for individual stores (cf. Figure 6). The transit times vary between 4.5 hours and 10 days (cf. Figure 5). The histogram of the transit time shows that the majority of all transits take between 1 to 4 days.

Figure 6 shows that the distance between the store and the DC does not influence the transit time significantly. The first four stores in Figure 6 are the ones closest to the DC. The other stores are about 250-300 miles away from the DC. The smallest spread between the maximum and the minimum

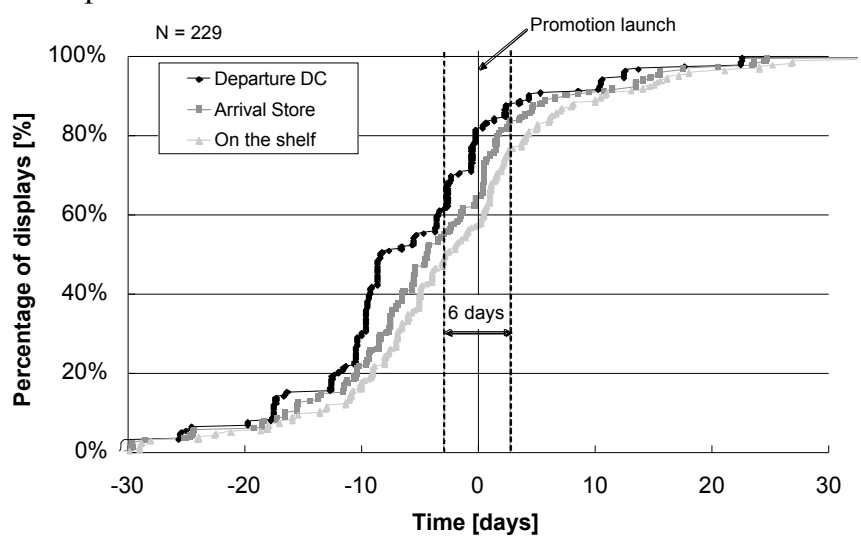

Figure 4: Cumulative distribution function of departure DC timing, arrival at store and placement on the shop floor.

transit time is 5 days and the biggest difference it 8 days. For the store with the biggest difference between spread in transit times, the mean average transit time is 4.8 days and for the one with the smallest it is 0.8 days.

Since all stores are within a radius of 300 miles around the DC, the transit time could in theory be less than 1 day for all deliveries. There are three causes for the variation. Firstly, each delivery truck stops on its journey at more than one store. Secondly, in some cases, trailers are occasionally dropped for a while and left in a yard before the content is delivered. Thirdly, due to unforeseen circumstances, the route is changed and the delivery is postponed.

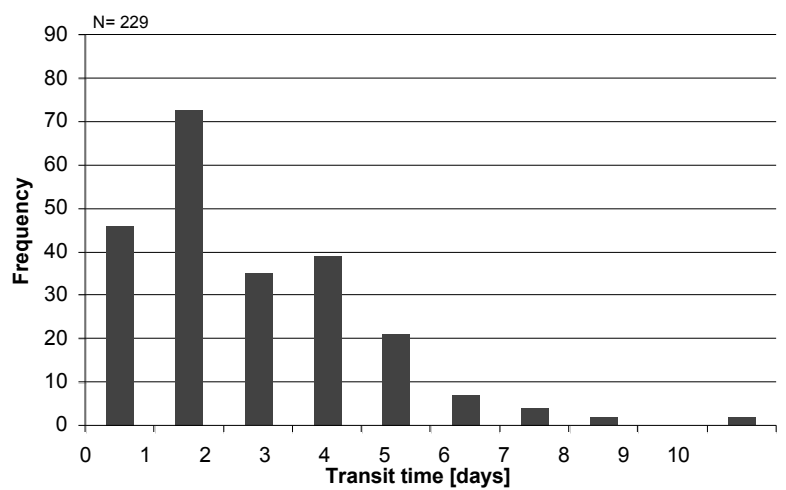

Figure 5: Histogram of transit time 


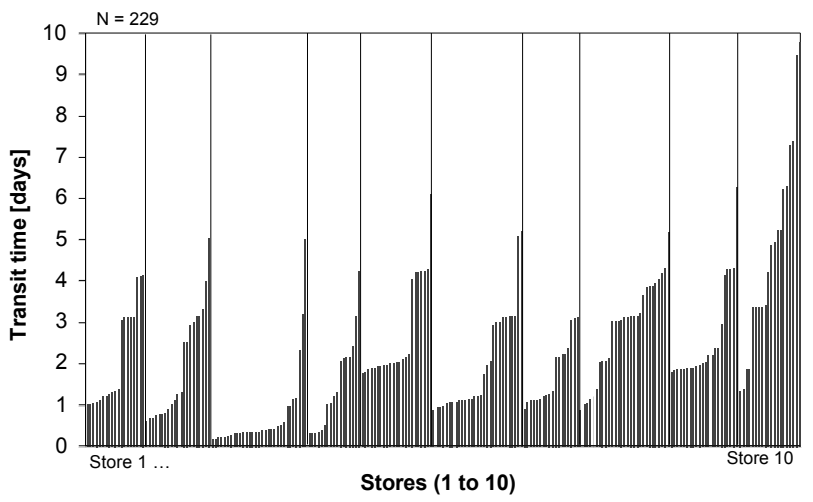

Figure 6: Transit time for each display (grouped by store)

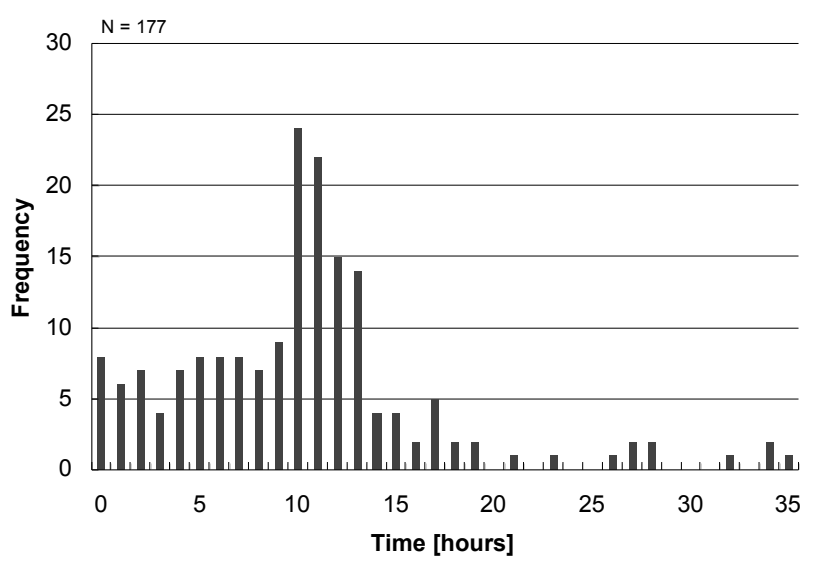

Figure 7: Dwell time in the backroom (time axis limited to 35 hours $\max (\mathrm{N}=177)$ for illustration purposes)

\section{Back Room}

Figure 4 shows that approximately two thirds of the displays were delivered to the retail store before the launch of the promotion. The majority of these displays arrived days in some cases weeks before the actual launch. Figure 7 shows that retail staff at the retail store tends to place displays on the shop floor with a median value of 12 hours after the arrival of the promotion display at the store.

The sample mean of the dwell time is 45 hours after arrival of cases at the store due to some outliers resulting from displays left in the back room. $72 \%$ of all promotions are brought on the sales floor within the first 20 hours after arrival at the store.

We believe that longer term storage was not necessarily done to target the promotion launch but happened accidently. The data analysis shows that 28 promotional displays were stored in the backroom for more than 3 days. These 28 promotional displays were placed on the sales floor within a range of 6 days too early and 71 days too late and thus did not improve the timeliness of promotion display placement.

The strong correlation between the arrival date and the date of placing promotions on the sales floor is also illustrated in Figure 8, where the coefficient of determination is $79 \%$. The two observable outliers reduce the value of the coefficient of determination significantly. The grey line represents the best performance from a store perspective where early arriving displays are kept in the backroom until the official launch data and late arrivals are placed on the shop floor immediately.

The dashed line represents the optimal performance from a system point of view, where all displays arrive before the launch and are placed on the floor on the day of the promotion launch.

The dwell time in the back room per store is shown in Figure 9. Even if the median of the dwell time across all stores is around 12 hours, the figure shows that in some stores the displays are occasionally forgotten in the back room. This seems to be happening in some stores more often than in others.

Figure 10 and Figure 11 show when displays arrive at the store and when they are placed on the shop floor. The figures show that the majority of the promotional displays were delivered to the retail store around noon and placed on the shop floor in the hours between $9 \mathrm{pm}$ and $1 \mathrm{am}$.

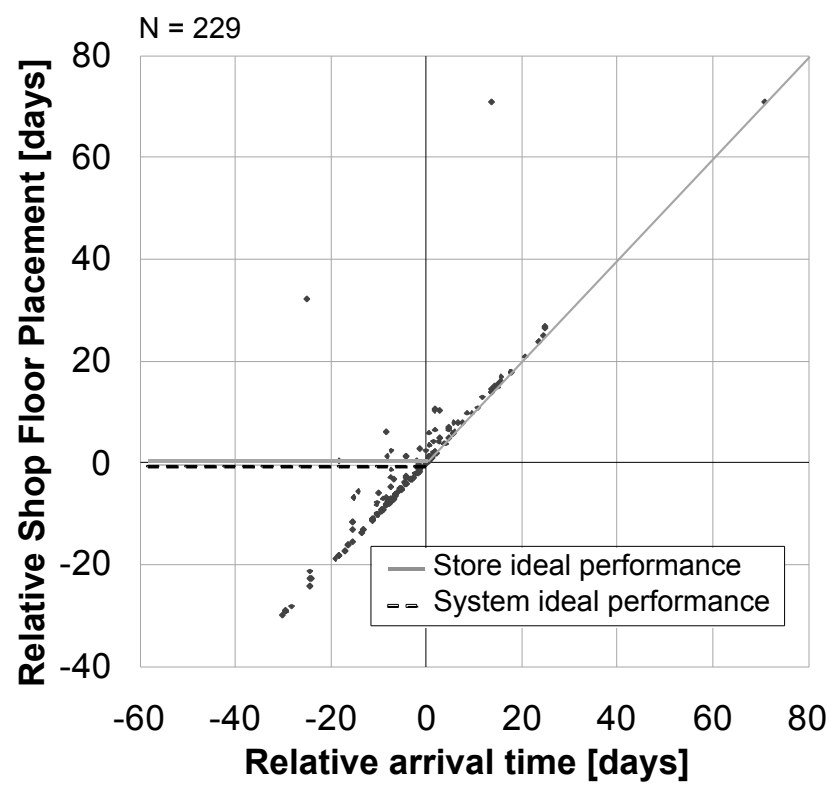

Figure 8: Correlation between arrival and shop floor placement

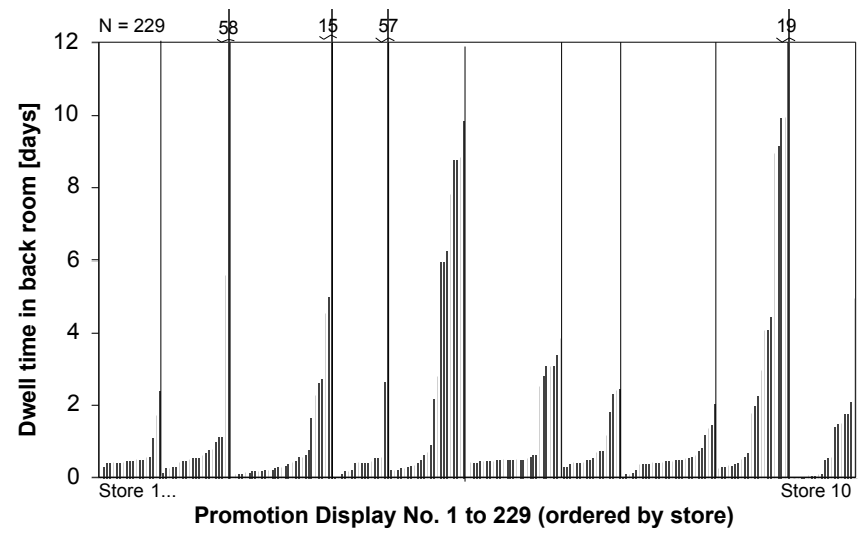

Figure 9: Variation in dwell time of 229 promotion displays per store 


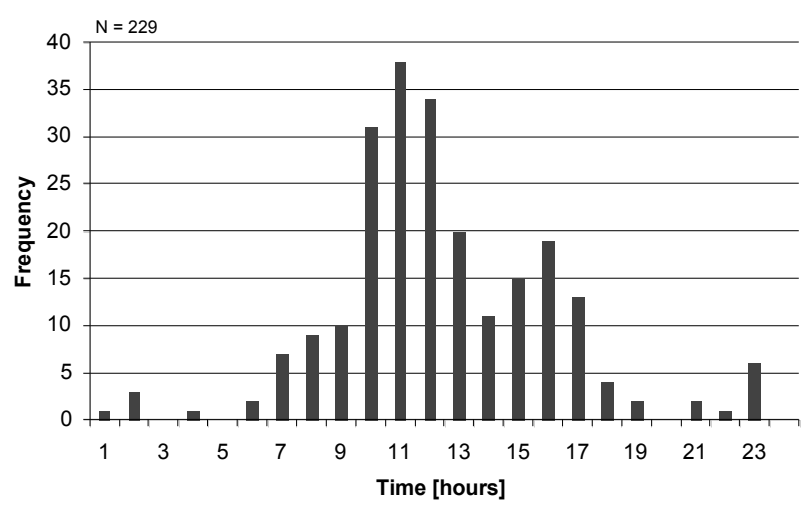

Figure 10: Histogram of hours of arrival of the promotion displays at the store

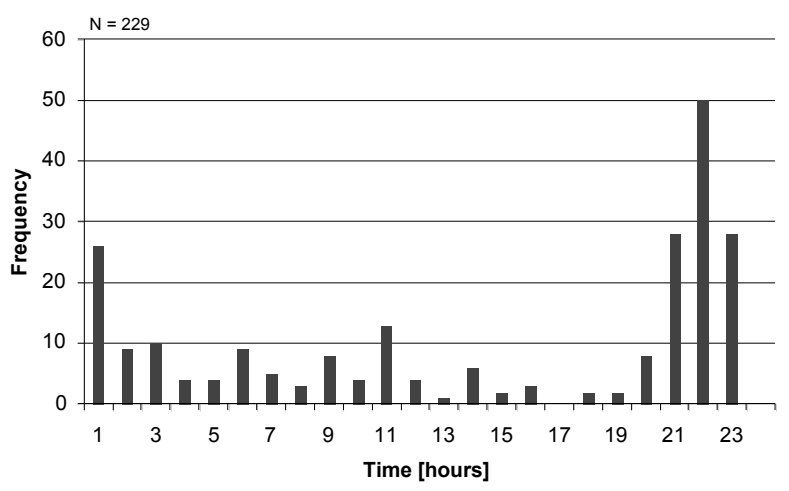

Figure 11: Histogram of hours of shelf placement of the promotion displays

\section{DISCUSSION}

The results presented in the previous section showed that in the case of the retailers studied the majority of the promotional displays were placed either too early or too late on the shop floor (cf. Figure 13). Only $28 \%$ of all promotional displays were displayed within $+/-3$ days of the promotion launch.

Our analysis identifies three reasons for the lack of timeliness:

- The distribution center did not ship the promotion displays in time. This was the case is approximately $30 \%$ of all promotion shipments.

- The wide variation in transit time was not considered resulting in displays arriving delayed at the retail store.

- The displays arriving prior to the launch were not kept in the backroom until the official launch date, but placed on the shop floor within 24 days of arrival at the store. This affects approximately $60 \%$ of the displays.

The causes for the late shipping at the distribution center could be late arriving shipments of displays from the supplier or scheduling issues. As part of this investigation, we were not able to determine the true underlying cause. The variation in transmit is most likely a result of scheduling and operational issues. The immediate placement of displays on the shop floor after their arrival can be caused either by a lack of knowledge of the retail store staff about the true promotion launch date, a lack of incentive to observe this date, or simply by the limited space in the backroom.

There are number of potential ways to improve the performance of promotion execution. One common way would be to provide better instructions to the retail store personnel to make sure early arriving displays are kept in the backroom until the official launch date. The other approach is to use RFID to detect the stores that do not place the displays correctly in real-time and send a "Supplier Retail Operations" team to correct the early placement. However, all of these approaches are resource intensive.

The data of this case study suggests an alternative approach that looks promising because of its simplicity. The results presented show that the retail staff places the majority of the displays on the shop floor within 12 hours of arrival at the store - typically late at night after the displays arrived during the day.

By making sure that the displays arrive at the store the day before the promotion launch, the displays will be present on the shop floor for the first time on the day of the launch. To better assess the predicted outcome of this approach, we simulated what would have happened if every promotion would have been sent 4 days prior to the promotion start day, using the observed variation in transit time (cf. Figure 12).

The simulation shows that only $4 \%$ of all promotions are more than 3 days too early on the sales floor and only $9 \%$ are more than three days late on the sales floor. $87 \%$ of all promotions are on the floor within +/- 3 days of the promotion start. By controlling the transit time better, the promotion execution could be improved even further. This shows that it is not necessarily required to monitor the movement of displays in real-time in retail stores with RFID as suggested in [8] to improve promotion execution. The results show that RFID is an excellent business process diagnosis tool.

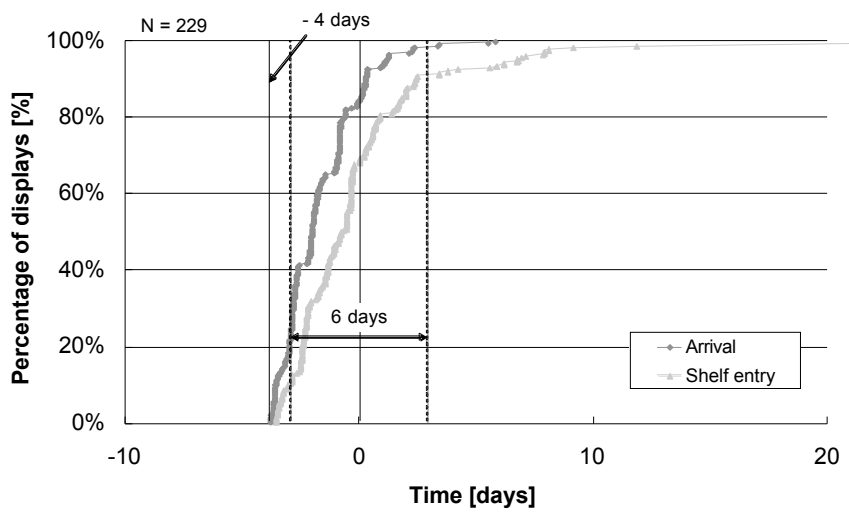

Figure 12: Simulation results showing cumulative distribution of the arrival and shelf entry time if all shipments are shipped four days prior to the promotion launch 


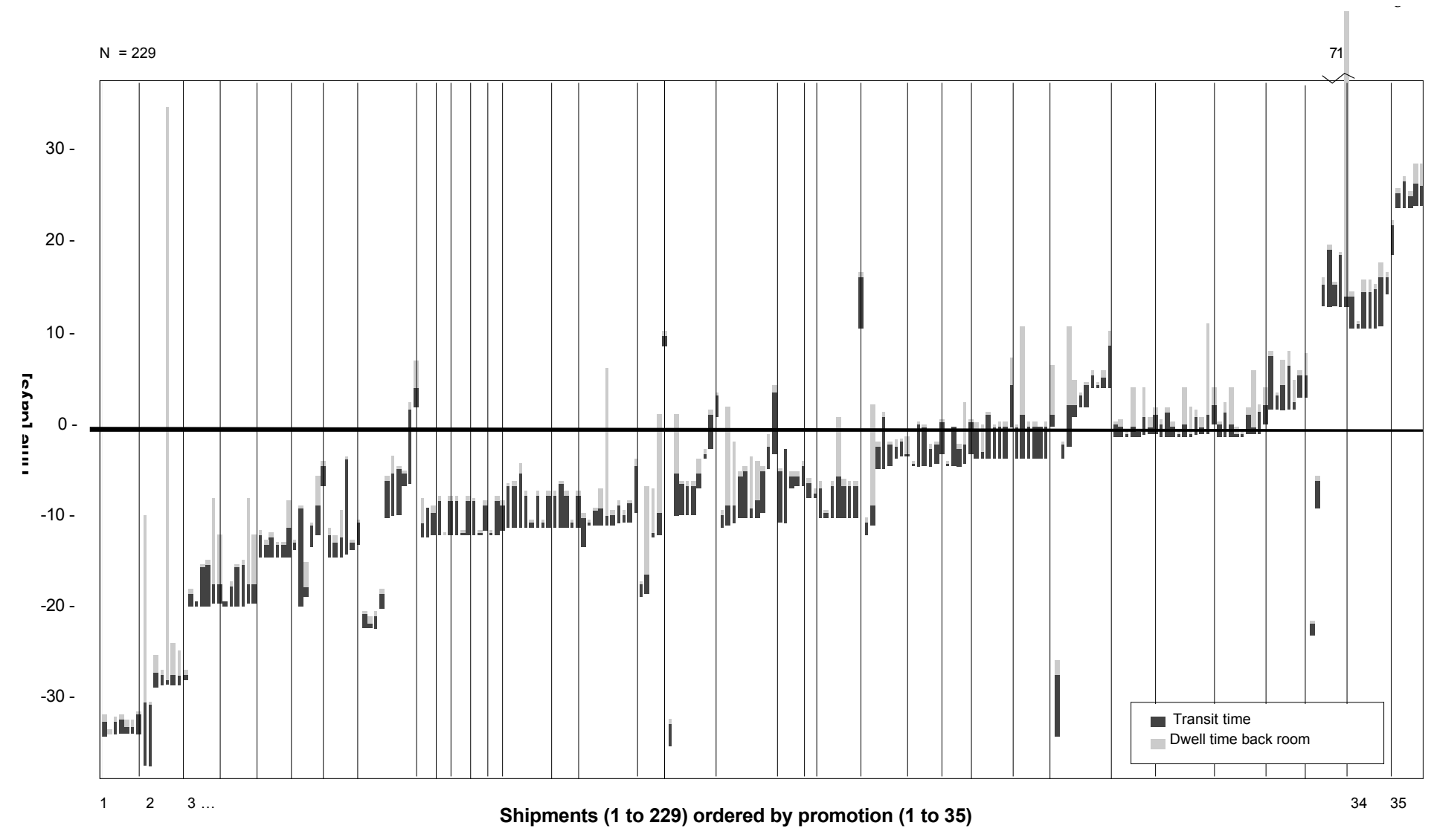

Figure 13: Overview of Promotion Display Movements

\section{CONCLUSION}

This paper analyzes the promotion execution in 10 stores of a US retailer. By tracking the movement of 229 promotional displays with RFID, we confirmed previous work that showed that promotional displays are not placed timely on the shop floor. Our results show that only $28 \%$ of all displays arrived on the shop floor within $+/-3$ days of the promotion start.

The RFID diagnostics data illustrated three main causes for the lack of timeliness. The distribution center ships the displays too late, the transit time varies significantly, and early arriving displays are placed on the shop floor within 24 hours of arrival and not kept in the backroom until the promotion launch.

Our work also suggests that promotion execution in this retail store chain can be significantly improved by using the fact that staff in the retail store places the majority of the displays on the shop floor within 24 hours of the display arrival. The distribution center simply needs to schedule the shipment such that they arrive the day before the promotion launch. A simulation where the displays were all shipped 4 days prior to the promotion launch showed that this would result in $87 \%$ of all displays on the shop floor within $+/-3$ days of the promotion start. This assumes the current large variation in transit time. This result contradicts the opinion reported in Dugall [8], where the room for improvement was seen in the retail store rather than in the distribution center.
Our results also show that RFID is an excellent business process diagnostics tool. RFID technology can be deployed selectively to identify business process problems. The actual

improvement results from business process changes rather than continuous RFID enhanced decision making.

\section{ACKNOWLEDGMENT}

The authors would like to thank Prithvi Raj Banerjee and Jasjit Mangat for their support with the data acquisition.

\section{REFERENCES}

[1] M. Kärkkäinen "Increasing efficiency in the supply chain for short shelf life goods using RFID tagging" in International Journal of Retail \& Distribution Management, Vol. 31 (2003), No. 10, pp. 529-536

[2] B. Subirana, S. Sarma, C. Ferguson, S. Langford, M. Spears, G. Jastremski, J. Dubash and R. Lee , "EPC Changing the CPG industry: Improving retail promotional execution, EPCglobal, White Paper, 2006

[3] Anonymous, "Promo Industry Trends Report", in PROMO Magazine, September 2007, Available: http://promomagazine.com/lp/research/2007_Ind_Trnd_Rpt/

[4] Anonymous "RFID reconciles CPG and retailer relationships- HP reduced phantom inventory and backroom discrepancies" in Chain Store Age, Vol. 83, September 2007, No. 9, p. 6A.,

[5] M. Roberti, "The serendipity effect" in RFID Journal, October 31th 2005, Available: http://www.rfidjournal.com/article/articleprint/1960/$1 / 128 /$

[6] D. Bell, X. Dreze, "Pay-for-Performance Trade Promotions: Why They Work and How To Implement Them", in Sloan Management Review Vol. 43 (2), October 2001, p. $42-49$

[7] M. Roberti, "P\&G adopts EPC advantaged strategy" in RFID Journal, January $24^{\text {th }} 2006$, Available:

http://www.rfidjournal.com/article/articleprint/2103/-1/128/ 
[8] M. Duvall "Wal-Mart's Faltering RFID Initiative" in Baseline Magazine, October $\quad 3$ rd 2007 Available: http://www.baselinemag.com/c/a/Projects-Supply-Chain/Cover-StoryWalMarts-Faltering-RFID-Initiative/

[9] T. Gruen, D. Corsten, S. Bharadwaj "Retail Out of Stocks- A Worldwide Examination of Extent Causes, and Consumer Responses", 2002
[10] S. Srinivasan, K. Pauwels, D. Hanssens, M. Dekimpe "Do promotions benefit manufacturers, retailers, or both?", March 5, 2003 ERIM Report Series Reference No. ERS-2002-21-MKT.

[11] H. Kurataa; X. Yue "Trade promotion mode choice and information sharing in fashion retail supply chains", in Int. J. Production Economics, Vol. 114 (2008), Pages 507-519 